\title{
A função de marcador aspectual de sintagmas adverbiais nas construções participiais absolutas licenciadas em textos de autores portugueses dos séculos XV, XVI e XVII
}

DOI: http://dx.doi.org/10.21165/el.v48i2.2177

\section{Alba Verôna Brito Gibrail'}

\section{Resumo}

As construções participiais absolutas formadas em textos de autores portugueses nascidos nos séculos XV, XVI e XVII apresentam sintagmas adverbiais definidos na literatura como advérbios de VP em posição mais alta na estrutura dessas orações. A interpretação de tópico do argumento verbal é o fator empírico que define a adjunção desses advérbios a categorias funcionais projetadas acima de VP, funcionando nessas construções como um marcador aspectual.

Palavras-chave: construção participial absoluta; aspecto verbal; marcador aspectual; tópico familiar; contraste.

1 Universidade Estadual de Campinas (UNICAMP), Campinas, São Paulo, Brasil; avb@gibrail.com.br; https://orcid.org/0000-0003-4919-0709 


\title{
The aspectual marker function of adverbs in absolute participle constructions formed in texts of Portuguese authors from the $15^{\text {th }}, 16^{\text {th }}$ and $17^{\text {th }}$ centuries
}

\begin{abstract}
The absolute participle sentences formed in texts of Portuguese authors born in $15^{\text {th }}, 16^{\text {th }}$ and $17^{\text {th }}$ centuries present adverbial phrases defined in the literature as adverbs of VP in higher positions in the structure of these sentences. The interpretation of topic of the verbal argument is the empirical factor that defines the higher position occupied by the adverbial phrase. In these sentences, the adverbial phrases are performed in position of adjunction to the functional categories AspP and/or Comp, having in these positions the function of aspectual marker.
\end{abstract}

Keywords: Absolute participle construction; verbal aspect; aspectual marker; familiar topic; contrast.

\section{Introdução}

O objetivo principal deste trabalho é mostrar que as construções participiais absolutas geradas em textos de autores portugueses nascidos nos séculos $X V, X V I$ e XVII licenciam advérbios descritos na literatura como advérbios de VP em posições mais altas na estrutura dessas orações. A codificação de tópico do argumento verbal das construções participiais absolutas formadas com advérbios nesses textos é o fator empírico que define a posição mais alta de adjunção desses elementos adverbiais na estrutura oracional.

Este fato é atestado junto ao Corpus Tycho Brahe² (CTB) no texto "Crônica del-Rei D. Afonso Henriques", de Duarte Galvão, autor nascido em 1435, obra que se caracteriza como uma narrativa correspondente ao gênero crônica. Duarte Galvão é o único autor nascido no século XV investigado na pesquisa. Esse tipo de construção é atestado também em textos de autores nascidos entre os séculos XVI e XVII, cujos nomes e respectivas obras são indicados no Anexo "Autores e obras analisados", no final do artigo.

Os dados foram levantados por meio da ferramenta computacional c-search dos textos já sintaticamente analisados e disponibilizados na página do projeto "O Português no tempo e espaço: contato linguístico, gramáticas em competição e mudança paramétrica", dirigido pela Profa. Dra. Charlotte Galves e financiado pela FAPESP.

20 Corpus Tycho Brahe é um corpus eletrônico de textos escritos em português por autores nascidos entre 1380 e 1881, postado na página do projeto temático "O Português no tempo e no espaço: contato linguístico, gramáticas em competição e mudança paramétrica", financiado pela FAPESP e dirigido pela Profa. Dr. Charlotte Marie C. Galves. O acesso ao Corpus Tycho Brahe pode ser feito através da URL: www.tycho.iel.unicamp.br/hotsite/index.html. 
Os textos que dispõem apenas etiquetas morfológicas foram levantados por meio da "Query Pos Files with Corpus Search", conforme indicado no Anexo "Autores e obras analisados".

Seguindo essa metodologia, levantamos 26 ocorrências de oração participial absoluta do texto de Duarte Galvão e 103 ocorrências dos textos dos autores nascidos nos séculos XVI e XVII. Ainda que a obra Crônica del-Rei D. Afonso Henriques, de Duarte Galvão, tenha sido compilada no século XVI, conforme é registrado na nota de rodapé ${ }^{3}$, no Corpus Tycho Brahe, os textos são catalogados e estudados de acordo com o século de nascimento dos autores, como propõe Galves, Britto e Paixão de Sousa (1995) e Paixão de Sousa (1994). As autoras apresentam duas razões para essa escolha. Primeiro, porque a escolha da data de nascimento corresponde à visão gerativa de que as gramáticas emergem no processo de aquisição da língua natural. Em segundo lugar, de acordo com as autoras, no que diz respeito aos textos do acervo do CTB, em muitos casos, essa é a única localização temporal em que se pode confiar. Por outro lado, Duarte Galvão, que foi compilador de escritos históricos, caracteriza o cronista da época, como propõe Michelan (2009, p. 277278):

\begin{abstract}
O cronista daquele tempo é tanto escritor como receptor da matéria escrita, ele recebe um texto e o reaproveita, é assim um leitor diferente daquele que apenas lê, pois lê para reescrever o texto, ou seja, escolhe passagens e reutiliza textos. [...] O leitor das crônicas mais facilmente reconhecível é, nesse sentido, o próprio cronista, a quem cabia compilar as crônicas passadas: lê-las e retomá-las em uma nova forma escrita, mesmo que esta nova forma compilada estivesse recheada de passagens na íntegra de textos anteriores.
\end{abstract}

As siglas mencionadas no desenvolvimento do artigo são siglas adotadas nos estudos linguísticos referentes a categorias funcionais e/ou lexicais de uma estrutura sintática, que explicitamos no quadro a seguir.

3 Chronica do muito alto, e muito esclarecido Principe D. Affonso Henriques Primeiro Rey de Portugal composta por Duarte Galvão, Fidalgo da Casa Real, e Chronista Mor do Reyno, Fielmente Copiada do seu Original, Que Se Conserva no Archivo Real da Torre do Tombo; offerecida a magestade sempre augusta delrey D. João V. nosso senhor por Miguel Lopes Ferreyra. Lisboa Occidental: na Officina Ferreyriana, 1726. - [23], 95 [1] p., 27 cm http://purl.pt/308 
Quadro 1. Siglas

\begin{tabular}{|c|c|}
\hline VP & Sintagma verbal \\
\hline DP & Sintagma nominal; \\
\hline V & Verbo no modo infinitivo \\
\hline S & Sujeito (argumento verbal) \\
\hline AspP & Categoria funcional Aspecto \\
\hline Spec & Especificador \\
\hline C & Núcleo do complementizador (Comp) \\
\hline kP & Projeção do núcleo k (contraste) \\
\hline Oração V2 & Verbo em segunda posição na oração \\
\hline
\end{tabular}

Fonte: Elaboração própria.

Os dados aqui analisados são de orações participiais que se conformam com as construções participiais absolutas do Português Europeu Contemporâneo (PEC) descritas por Santos (1999, p. 32-33) como: "orações que têm como núcleo uma forma participial e um argumento interno lexicalmente realizado e apresentam uma interpretação perfectiva, mantendo com a oração subordinante uma relação de modificador adverbial".

O artigo compõe-se de três seções. Na primeira seção, intitulada "As construções participiais absolutas licenciadas no texto 'Crônica del-Rei D. Afonso Henriques', de Duarte Galvão", são analisados dados de construções participiais absolutas licenciadas nesse texto, observando as propriedades sintático-discursivas que nos permitem definir a adjunção em posições mais altas nessas construções de advérbios que, em contextos de orações finitas, ocorrem em adjunção ao VP. Na segunda seção, nomeada "O licenciamento das construções participiais absolutas nos textos dos séculos XVI e XVII", é apresentado o resultado da investigação feita nos textos dos autores nascidos entre os séculos XVI e XVII, ressaltando o fato de haver uso dessa construção com alternância da ordem de realização do argumento verbal apenas no texto "História da Província de Santa Cruz", de Pero Magalhães de Gandavo, autor nascido em 1502. Nos textos dos outros autores nascidos nesse período e investigados nessa pesquisa, o argumento das construções participiais absolutas é realizado exclusivamente em posição pós-verbal. Na terceira e última seção, apresentamos as considerações finais, retomando as análises propostas na descrição dos dados disponibilizados nas seções precedentes. Destaca-se, nessa seção, os fatores sintático-discursivos que motivam a alternância da ordem do 
argumento verbal no uso dessas construções no texto de Duarte Galvão e no texto de Pero Magalhães de Gandavo, e restringe sua realização em posição pós-verbal nos textos dos outros autores nascidos nesse período.

\section{As construções participiais absolutas licenciadas no texto "Crônica del-Rei D. Afonso Henriques"}

O texto "Crônica del-Rei D. Afonso Henriques", de Duarte Galvão, apresenta uso de construção participial absoluta com alternância da ordem de realização do argumento verbal em contextos formados com verbos transitivos e/ou inacusativos. Assumindo o argumento verbal dessas construções como sujeito, conforme propõe Ambar (1992) para as construções participiais absolutas do PEC e Hernanz (1991) para o Espanhol, a alternância atestada no texto de Duarte Galvão pode ser descrita como alternância das ordens SV/VS.

Em se tratando do uso de verbos transitivos, a frequência maior é atestada com o verbo "fazer". Nessas produções, o argumento (sujeito) de uso mais frequente são sintagmas nominais e/ou o pronome "isto".

\section{Ordem SV}

(1) e efto feito, entregou elRey fua filha aho conde,

(2) Ellas feytas, EIRey D. Affonfo partio de Coimbra para aquelleluguar,

(3) El-Rei sabido de sua vida, e propósito folgou muito, e mandou por ele dizendo-lhe

como edificara aquele Mosteiro de São Vicente,

Ordem VS

(4) Feyto efto ElRey cavalguou loguo em hum cavallo grande e fermolo,

(5) E dito efto delapareceo,

(6) Ditas eftas palavras dezapareceu, e eu cheyo de confiança, e fuavidade me torney para

o Real.

(7) E vifta ha Procuraçam_El-Rey tomou fua filha, e trouxe a ante ho Arcebípo de

Bragua,

Em contextos com verbos inacusativos, há formação dessas construções com os verbos acabar, chegar, partir, finar e desaparecer com taxa de frequência semelhante. 


\section{Ordem SV}

(8) IIto acabado, avendo-le ho Conde de hir colher ha fuas pouzadas re quizera ally defpedir delRey,

(9) e elle partido, EIRey fe tornou para Coimbra com toda fua gente, e Corte.

(10) Elles cheguados aho porto da Cidade de Lisboa, nom quizeram loguo tirar fóra

ho Corpo do gloriolo Martir,

\section{Ordem VS}

(11) Finado Dom Eguas, e mandado assi enterrar como dito é, o Príncipe Dom Affonso Anriques como quer que lhe muito pezasse do falecimento de tão honrado Cavaleiro, em quem tinha grande confiança;

(12) Desaparecida esta visão ficou muito consolado Dom Eguas Moniz, e alegre, com o vassalo

que com são, e verdadeiro amor amava seu Senhor, e suas coisas,

(13) Saído ele meteu-se em cima da Serra, que chamam Amendigua,

Santos (1999), ao descrever a alternância da ordem no uso dessa construção no PEC, propõe que o argumento em posição pré-verbal codifica informação discursiva, não sendo sua realização nessa posição uma opção de uso. Em sua argumentação, as construções participiais de ordem [DP V], como sintagma nominal antecedendo o verbo no particípio são mais aceitáveis quando o contexto obriga a interpretar o DP como tópico; quando a ordem é [V DP], com o sintagma nominal em posição pós-verbal, o DP é o constituinte focalizado na oração.

Importa destacar que, nas ocorrências de ordem [DP V] e/ou [V DP] no texto de Duarte Galvão, o argumento verbal pode ser interpretado como tópico familiar/tópico contínuo. Nos conceitos de Galves e Gibrail (2018), a interpretação de tópico familiar/tópico contínuo é atribuída a termos que se repetem e/ou a termos que se caracterizam como resumos de trechos do discurso prévio. Para essas autoras, a noção de "familiar" aproxima-se da noção de anáfora.

O trecho a seguir do texto de Duarte Galvão confirma a codificação de tópico familiar/ tópico contínuo do argumento verbal na ocorrência (1), de ordem [DP V] e na ocorrência (7), de ordem [V DP]. Assumindo o DP como sujeito dessas orações, proposto acima, a codificação de tópico familiar é dada ao sujeito dessas construções nas ordens SV em (1) e/ou VS em (7). 
(14) "[...] e des aquelle dia diante, começàram ha no trato do cazamento da Ifante, e do filho do Conde, eftiveram em ho concertar àtée dous dias por andar de Janeyro em que le fez ho cazamento; no quoal dia fendo hy juntos muitos Senhores, e Prelados, e Cavalleyros de huma parte, e da outra, foy lida á Rainha, e Ifantes huma_Procuraçam de D. Reymondo filho do dito Conde porque dava poder ha feu Pay, que em leu nome podefle receber com elle ha Ifante D. Mofalda filha delRey D. Affonfo. E vifta ha Procuraçam El-Rey tomou fua filha, e trouxe a ante ho Arcebifpo de Bragua, ho qual tomou ho Conde pela mam, e affi ha Ifante, e entaõ hos recebeu, elle como Procurador de feu filho, e ella por ly, como manda a Santa Madre Egreja de Roma, e efto feito, entregou elRey fua filha aho conde,"

O argumento verbal (sujeito) "Procuraçam", na ordem VS da construção participial é um elemento já mencionado no discurso prévio, que vai se repetir ao longo da narrativa. Dentro dos conceitos apresentados na literatura para as categorias tópico e foco (REINHART, 1981; ZUBIZARRETA, 1994; KISS, 1998), o sintagma "Procuraçam" é um elemento "dado"; ocupando na estrutura da informação a posição de tópico. Por outro lado, o sujeito "efto", na ordem SV, é um pronome demonstrativo que expressa, resume e retoma trechos do discurso que o antecede, o que permite que ele seja também interpretado como tópico, seguindo a proposta de Galves e Gibrail no trabalho citado acima. Em ambas as ocorrências, o sujeito, em posição pós-verbal "Procuraçam" e/ou em posição pré-verbal "efto", pode ser interpretado como tópico familiar/tópico contínuo.

Outros dados levantados do texto de Duarte Galvão apresentam construções participiais absolutas nas ordens VXS/SXV/XSV com advérbio "assim" ocupando a posição X.

\section{Ordem VXS}

(15) Paflado alfi efto, fez El-Rey juntar toda lua gente que com elle era, e dice-Ihe:

(16) Entrada e tomada affi ha Villa de Santarem, Auzary Alcayde mor della, efcapou fugindo, com tres de cavallo configuo caminho de Sevilha, quãto mais pode.

(17) Feyta affi efta deftruiçaõ , nos Mouros,e avidas eftas vitorias nas terras Dalentejo ,

leixou EIRey Bejae todolos outros Luguares, muy baftecidos, e providos de

Cavalleyros, e gente que hos muy bem podelfem defender, e guardar, e tornou-le

para Coimbra com muita honra, e grande prazer , 


\section{Ordem SXV}

(18) Elto alfi palfado, quantos ahy eftavaõ foraõ beyjar ha maõ ha ElRey , e le defpediraõ delle .

(19) Elto afli detreminado, dice ho Ifante ha D. Pero Paes Alferes, que tomalfe carreguo, dos que aviam de fiquar, e elle Ihe refpondeo:

(20) Elto affi palfado, ho Ifante le apartou loguo com hos principais para ho averem de fazer,

\section{Ordem XSV}

(21) e affi efta Villa tomada ho Princepe ha deu aho Prior de Santa Cruz de Coimbra,

Nas ocorrências de ordem VXS, o argumento (sujeito) em posição pós-verbal com a interpretação de tópico familiar/tópico contínuo é evidência empírica de sua realização em posição mais alta na estrutura dessas orações. Nos exemplos (15), (18), (19) e (20), o pronome "isto" retoma e resume um trecho do discurso anterior. Em (21), o argumento verbal "esta vila" é um nome já mencionado no discurso, como é atestado no excerto do texto onde esta construção é formada.

(22) "E dahi veyole ha Coimbra onde lhe pareceo que eltava muy de vaguo, e fem proveyto, pois fe nom occupava em mais, que no que tinha mandado ahos feus que fizeffem pelo qual ajuntou algũa gente , e fez entrada na terra dos Mouros, e no primeyro luguar em que deu foy Leyria ha qual combateo rijamente, e polto que ho Caltello folfe muito forte, e hos Mouros ho muy bem defendeflem tomou-ho por força e hos mais dos Mouros que ahi achou andàram à efpada , e alfi efta Villa tomada ho Princepe ha deu aho Prior de Santa Cruz de Coimbra, por fer homem em que elle tinha grande devaçam,"

É importante salientar que o argumento verbal "efta Villa" tem sua referência no nome "Leyria", mencionado no discurso anterior, o que define sua interpretação como tópico familiar/tópico contínuo. Por outro lado, nessa posição, o argumento verbal expressa contraste/ênfase. O contraste expresso pelo sintagma "efta Villa", a primeira vila que os portugueses chegaram e tomaram nas terras dos mouros é estabelecido com as outras vilas existentes nessas terras ainda não entradas e tomadas pelos portugueses.

Segundo Galves (no prelo), sintagmas com funções gramaticais e informacionais diferentes em posição pré-verbal expressando contraste são licenciados nas orações raízes finitas de ordem $V 2$ formadas nos textos dos autores nascidos nos séculos XVI e XVII. De acordo com essa autora, a oração (23), a seguir, levantada do texto de Francisco 
Lobo, autor nascido no séc. XVI, apresenta a posição pré-verbal ocupada por um objeto direto com a interpretação de tópico familiar/tópico contínuo expressando contraste/ ênfase; na ocorrência (24), levantada dos Sermões, de Antonio Vieira, autor nascido no séc. XVII, o elemento em posição pré-verbal é um foco de informação expressando contraste/ênfase.

(23) Esta história contou a peregrina com os olhos cheios de água,

(24) Mas povoado sei eu d'onde elles não haviam de levar a embaixada debalde.

Galves (no prelo) defende que esses elementos em posição pré-verbal ocupam o especificador de kP (contraste), projetado em posição baixa em Comp. Na formulação dessa autora, o núcleo k (contraste) compartilha a propriedade de não ser obrigatoriamente projetado nessas sentenças.

Conforme mostram os exemplos (15), (16), (17), (18), (19), (20) e (21), acima, levantados do texto de Duarte Galvão, o advérbio "assim" apresenta flexibilidade na posição de sua realização na estrutura dessas construções participiais.

Consoante Costa (2008), alguns advérbios do PEC podem funcionar nos contextos de orações finitas como marcadores conectivos, estabelecendo relações de significado com base em fragmentos ou unidades discursivas precedentes que geralmente ultrapassam a frase.

(25) A Maria está grávida. Consequentemente, tem enjoos matinais. (COSTAS, 2008, p. 15, ex. 11)

(26) Assim, chegamos ao fim desta viagem. (COSTA, 2008, p. 15, ex. 12)

Na análise de Costa (2008), a maioria dos advérbios com essa função discursiva pode ser também realizado como modificador de um predicado, tendo uma leitura de tempo, localização ou modo.

(27) Assim, conseguimos abrir a porta. (COSTA, 2008, p. 17, ex. 18)

(28) Conseguimos abrir a porta assim. (COSTA, 2008, p. 17, ex. 18)

(29) Ter enxaquecas é aborrecido. Agora, ficar em casa é bom. (COSTA, 2008, p. 17, ex. 19)

(30) Fico em casa agora. (COSTA, 2008, p. 17, ex. 19) 
De acordo com esse autor (COSTA, 2008), os advérbios, em posição pré-verbal nas sentenças (27) e (29) funcionam como advérbio conectivo; nas sentenças (28) e (30), esses elementos têm, respectivamente, uma leitura de modo e tempo.

Diferente, contudo, do que é evidenciado nas sentenças finitas do PEC em (27) e (29), nas quais os advérbios "assim" e "agora" funcionam como um marcador conectivo, estabelecendo relações de significado com base em unidades discursivas precedentes, como propõe Costa, o advérbio "assim", nas ocorrências de construções participiais absolutas em uso no texto de Duarte Galvão, não pode ser assumido como marcador conectivo, haja vista que, nessas construções, este elemento não estabelece relações de significado com unidades do discurso precedente. Nessas orações participiais, o argumento verbal codificado como tópico familiar/tópico contínuo é o elemento que mantém uma conexão com o discurso anterior.

Santos (1999), ao formular sua proposta, compara a distribuição de advérbios ditos de VP nessas construções: os advérbios "completamente" e "bem".

(31) Uma vez lido bem o livro, o Mário conseguiu fazer o resumo. (SANTOS, 1999, p. 63, ex. 14)

(32) ?? Uma vez bem lido o livro, o Mário conseguiu fazer o resumo. (SANTOS, 1999, p. 63, ex. 13)

(33) Uma vez completamente lido o livro, o Mário conseguiu fazer o resumo. (SANTOS, 1999, p. 63, ex. 15)

A autora defende que o movimento do verbo não é opcional no particípio absoluto. Em sua análise, o verbo nas ocorrências (31) e (33) terá saído da posição em que é gerado, no interior do sintagma verbal (VP), sendo estas duas possibilidades de ordem [ADV V DP] e [V ADV DP] geradas por diferentes posições de adjunção dos advérbios. De acordo com sua proposta, a posição de realização desses advérbios indica que o DP (sintagma nominal) quando precede o verbo se encontra na projeção funcional mais alta que a projeção da categoria funcional que contém o verbo; se o DP se encontrasse na posição de especificador da projeção cujo núcleo é o alvo do movimento do verbo, a ordem [ADV DP V] deveria ser gramatical, já que a ordem [ADV V DP] também é gramatical. Em sua argumentação, a agramaticalidade da ocorrência em (32), por contraste com a gramaticalidade de (31), só pode ser explicada se admitir que o advérbio "bem" define um domínio de adjunção mais baixo do que "completamente", sendo o VP esse domínio mais baixo. Dentro de sua análise, o advérbio "completamente" é mais flexível na definição do seu domínio de adjunção, podendo ser realizado em adjunção ao VP ou a um nó mais alto, ao qual "bem" não se adjunge. 
De acordo com Santos (1999), o argumento verbal das construções participiais na ordem [DP V] licenciadas no PEC se encontra fora do VP, no especificador de uma projeção funcional mais alta, que a autora propõe ser Asp (Aspecto), assumindo que os particípios absolutos são projeções de Asp. De acordo com Santos (1999, p. 70), "o particípio passado conteria informação aspectual suficiente (a informação perfectiva intrínseca contida no morfema -d-) para projetar um nó Asp, na ausência de outro segmento de IP". Sua proposta é que, nessas construções, "Asp com o traço [+ perf] seja um núcleo que seleciona como complemento um predicado que pode ser transformado em estado resultante". A autora assume duas projeções funcionais acima do VP: a projeção de um núcleo que é alvo do movimento do verbo e a projeção de Asp.

Ao tratar desse tipo de construção do espanhol, de Miguel (1990 apud HERNANZ, 1991) também assume as orações aspectuais absolutas como projeções de um núcleo Asp com o traço [+ perfectivo].

Santos (1999), que defende ser [Spec, Asp] a posição de sujeito no particípio absoluto, propõe que a subida do argumento verbal para esta posição codifica a interpretação desse elemento como tópico, o que a leva a formular que "o traço relevante presente em Asp no Português não é um traço D-forte como o que distingue as línguas não pro-drop das línguas pro-drop, mas um traço de codificação de informação discursiva" (SANTOS, 1999, p. 74).

\section{0 licenciamento das construções participiais absolutas nos textos dos séculos $\mathrm{XVI-XVII}$}

Em se tratando do uso deste tipo de oração participial nos textos dos autores nascidos nos séculos XVI e XVII, a alternância da ordem é atestada apenas no texto "História da Província de Santa Cruz", de Pero Magalhães de Gandavo, que licencia uma ocorrência dessa construção na ordem SXV, com o argumento verbal expresso pelo pronome "isto" precedendo o advérbio "assim" e o verbo.

(34) Ifto a $\boldsymbol{\beta}$ dito, Apol que da flama Celeste guia os carros, da outra parte Se lhe aprefenta, \& por leu nome o chama.

Os dados levantados dos outros autores nascidos nesse período, que formam os corpora dessa pesquisa, não apresentam uso dessas construções com alternância da ordem. Em seus textos, essas construções são formadas de maneira categórica na ordem VS, em contextos com verbos transitivos e/ou verbos inacusativos.

(35) Despedido o Alvarado, e vinda a monção de se irem pera a India, embarcou Dom 
Jorge na náo da carreira Belchior Fernandes Correia com todos estes protestos por

muitas vias, (D. Couto, séc. XVI).

(36) Partido (como já dissemos) o valeroso capitão Hercules pera Italia, começou Hispalo seu filho a governar o Reyno de toda Espanha, (Bernardo de Brito, séc. XVI)

(37) Destinado este socorro ao Pará, reservou o Padre VIEIRA para a Cidade aos Padres Thomé Ribeiro, e Manoel de Lima, que na nossa Igreja haviam de pregar aquela Quaresma, e acudir com seu zelo àquele povo. (A. de Barros, séc. XVII)

(38) Acabada a pratica, o Vereador mais velho offereceo a elRey as Chaues e hum prato de prata; (A. de Sousa Macedo, séc. XVII)

(39) Acabada ela se rezou Ladainha, (A. de Sousa Macedo, séc. XVII)

Ainda que esses autores façam uso dessa construção exclusivamente na ordem VS, o sujeito em posição pós-verbal pode também ser interpretado como tópico familiar/tópico contínuo, dentro dos conceitos de Frascarelli e Hinterhözlz (1997) e Galves e Gibrail (2018), citados acima. No exemplo (35), extraído do trecho do texto "Décadas", de Diogo Couto, autor nascido no séc. XVI, apresentado de forma resumida em (40), o argumento (Alvarado) é um nome já mencionado no discurso anterior e que se repete ao longo da narrativa.

(40) E depois de se fortificar, despedio Mathias de Alvarado com um requerimento a $D$. Jorge, que êle recebeo muito bem, e êle the mostrou o requerimento que levava, em que o Villa-Lobos Ihe dizia: [...] Despedido o Alvarado, e vinda a monção de se irem pera a India, embarcou D. Jorge na náo da carreira Belchior Fernandes Correia com todos estes protestos por muitas vias, umas pera dar ao Governador,

Na oração participial em (36), levantada do texto "Da Monarquia Lusitana", de Bernardo de Brito, nascido no séc. XVI, o argumento (o valeroso capitão Herculles) também é nome de uma personagem mencionada muitas vezes no texto.

(41) "Partio-se Hercules pera Italia a tomar vingança dos Lestrigones, que entrarão na conjuração do Pay, levando comsigo grande copia de gados fermosissimos, que o tres Geriões trazião em Lusytania: que nunca ha vencedor tão desinteressado, que engeite despojos dovencido. [...] Partido (como já dissemos) o valeroso capitão Hercules pera Italia, começou Hispalo seu filho a governar Reyno de de toda Espanha," 
Na ocorrência (39), de A. de Sousa Macedo, nascido no séc. XVII, o argumento pronominal "ella" tem sua referência no nome "Mirfa de Pontifical".

(42) "No outro dia pella manhã, que era feftafeira 25 do mez, forão Sua Magestade \& Sua Alteza a cauallo â Ermida de Nossa Senhora da Piedade, diffe Miffa de Pontifical o Bifpo de Targa, cãtada pellos muficos da Capella Real. Acabada ella fe rezou Ladainha,"

O texto de André de Barros, nascido no séc. XVII, apresenta ocorrências dessa construção na ordem VXS, com o advérbio "assim" ocupando a posição X.

(43) Evitado assim o primeiro trabalho, entrou o segundo.

(44) Socorridos assim os companheiros de sua fortuna, restava resgatar as preciosas jóias de seus papéis, e livros, que levavam tomados na presa os inimigos;

Por questão de espaço e seguindo a mesma metodologia, acrescentamos a seguir apenas o excerto do texto de André de Barros no qual a ocorrência (44) é licenciada.

(45) Neste desamparo acudiu a ardente caridade do Padre António Vieira, varão, a quem esta História se não cansa de chamar heróico; coração verdadeiramente maior, que o Mundo, a quem nenhum perigo acovardava, nem adversidade oprimia. Sendo tanto o número da gente, com o grande crédito, que em toda a parte tinha a fama de seu nome, a todos acudiu. Aos quatro Religiosos deu hábito, e toda a roupa interior: a todos os mais camisas, sapatos, meias, e outras peças de vestidos, de que necessitavam. Escolheu dois homens de respeito; um entre os mariantes, outro entre os passageiros, aos quais entregava dinheiro sem limite, para que nada faltasse a toda aquela esquadra; durando este dispêndio na Ilha Graciosa por espaço de dois meses, e depois na Ilha Terceira, à qual passaram todos: e continuando a liberalidade, e grandeza de seu ânimo, aos mesmos deu embarcação, matalotagem de biscoito, carne, pescado, até tomarem porto em Lisboa. Socorridos assim os companheiros de sua fortuna, restava resgatar as preciosas jóias de seus papéis, e livros, que levavam tomados na presa os inimigos.

Considerando que o advérbio "assim" nas construções participiais absolutas licenciadas no texto de Duarte Galvão e nos textos dos autores dos séculos XVI e XVII pode ser analisado como a realização lexical da interpretação perfectiva desse tipo de construção, 
defendemos, como propusemos acima, que esse elemento funciona, nessas produções, como marcador aspectual.

A função de marcador aspectual é atribuída à expressão adverbial "uma vez" licenciada nas construções participiais absolutas do PEC.

(46) Uma vez paga a conta, o Pedro ficou arruinado. (AMBAR, 1992, p. 112, ex, 248c).

(47) Uma vez destruída a ponte, o comboio deixou de circular. (SANTOS, 1998, p. 11, ex. 43).

Conforme Santos (1999) indica, o marcador aspectual "uma vez" pode ser omitido nas construções participiais do PEC sem que haja alteração do significado semântico perfectivo emergido nesse tipo de oração.

Os dados de André de Barros, autor nascido no séc. XVII, apresentam ocorrências que dispõem de outras expressões adverbiais na ordem VXS, indicando o mesmo comportamento do advérbio "assim", adjungindo-se a projeções mais altas que VP, definidas pela posição ocupada pelo argumento verbal codificado como tópico.

(48) Concluído tão felizmente este negócio com os de fora, tratou logo de assentar sistema de governo interior com os companheiros em casa.

(49) Alcançada esta vitória, e cortado tão felizmente o partido do Inferno, tomaram alentos novos os Missionários.

Confirmando a proposta de Frascarelli e Hinterhölzl (2007) e Galves e Gibrail (2018), o argumento verbal dessas produções pode ser interpretado como tópico familiar/tópico contínuo por ser um elemento já referido no discurso prévio, um nome mencionado no início do texto que se repete ao longo da narrativa e/ou um elemento que resume um trecho do discurso anterior. O argumento verbal "o partido do Inferno" da ocorrência (49) é um elemento já referido no discurso prévio, como é evidenciado no trecho do texto de André de Barros em que esta construção é formada.

(50) Escondeu-nos o tempo os casos particulares, com que nesta campanha derrotou o partido do Inferno o nosso Guerreiro forte. [...] Alcançada esta vitória, e cortado tão felizmente o partido do Inferno, tomaram alentos novos os Missionários. 
Por outro lado, a pesquisa revela que nem todas as ocorrências de ordem VS dispõem do argumento verbal com a interpretação de tópico familiar/tópico contínuo.

(51) \& feita oração tornou do melmo modo, \& com o melmo acõpanhamento até o Paço em $\tilde{q}^{4}$ auia de poufar, (A. de Sousa Macedo, séc. XVII)

É importante salientar que, nesta produção, o argumento em posição pós-verbal não é um elemento retomado do discurso prévio. Trata-se de uma informação nova, de um foco de informação. De acordo com Kiss (1998, p. 248), "o foco de informação marca a natureza não pressuposta da informação que ele carrega". Para Santos (1999), como já mencionamos, o argumento em posição pós-verbal nas construções participiais do PEC ocupa sua posição de base no VP, isto é, está dentro da projeção do verbo, recebendo nessa posição o acento de foco da oração.

A definição de elemento novo no discurso do argumento verbal do exemplo (51) é assegurada no trecho do texto em que esta oração participial é licenciada.

(52) Na porta da Igreja eftaua D. Frãcifco Souto Maior Bifpo de Targa, eleito de Lamego, que ferue de Capellão Mòr, reueftido debaixo de Paleo, com a reliquia do Santo Lenho; alli recebeo a Sua Magestade que foi atê a Capella Mór, \& feita oração tornou do melmo modo, \& com o melmoacõpanhamento até o Paço em q q $^{3}$ Elto alfi palfado , quantos ahy eftavaõ foraõ beyjar ha maõ ha ElRey, e le delpediraõ delle . auia de poufar,

Os dados de André de Barros apresentam duas ocorrências de construção participial absoluta de ordem VS formadas em contexto de coordenação.

(53) Levantadas as âncoras do Tejo, e dadas as velas ao vento, saiu, e deixou a pátria com universal edificação, e se engolfou no Oceano o Padre António Vieira, meado Abril.

Nestas duas produções, o argumento verbal não pode ser interpretado como tópico familiar/tópico contínuo. O argumento verbal da primeira oração participial, "as âncoras", e o da segunda oração, "as velas", são elementos novos, não referidos no discurso anterior, o que os exclui de serem interpretados como tópico. Sendo um elemento novo no discurso, o argumento verbal dessas duas ocorrências ocupa a posição de foco no VP.

40 pronome relativo q é grafado com redução vocálica. 
Ainda que os dados levantados dos textos dos autores dos séculos XVI eXVII apresentem construções participiais absolutas na ordem $V(X) S$ com o argumento verbal interpretado como foco de informação, a frequência maior de ocorrências, como já mencionado acima, é verificada com este constituinte em posição pós-verbal com a interpretação de tópico familiar/tópico contínuo. Um dos fatos mais relevantes emergidos na descrição desses dados é a relação estabelecida entre o uso do argumento verbal com a interpretação de tópico familiar/tópico contínuo e o uso de expressões adverbiais com a função de marcador aspectual.

\section{Propostas da análise}

Em consonância com a proposta de Santos (1999), referida na introdução deste artigo, a alternância da ordem [DP V] no uso de construções participiais absolutas no PEC é desencadeada por questões discursivas. O uso da ordem [DP V], segundo essa autora, ocorre quando o DP é um elemento "dado" no discurso, um tópico. Nas ocorrências de ordem [V DP], o DP é o constituinte focalizado da oração. Em se tratando da alternância da ordem de realização do argumento verbal nas construções participiais absolutas em uso no texto de Duarte Galvão e no texto de Pero Magalhães de Gandavo, defendemos que ela é motivada por fatores discursivos, como propõe Santos para as construções do PEC. Diferente, entretanto, da alternância dessas construções no PEC que, de acordo com Santos, o uso da ordem [DP V] corresponde à interpretação do argumento verbal como tópico e o uso da ordem [V DP] corresponde à interpretação desse elemento como foco, nos dados de Duarte Galvão e Pero Magalhães de Gandavo, o argumento em posição pré e/ou pós-verbal pode ser codificado como tópico familiar/tópico contínuo.

Divergindo, entretanto, da proposta de análise de Santos (1999), que assume realização do verbo em um núcleo de uma categoria funcional projetada acima de VP, porém em posição mais baixa que AsP, nas construções participiais absolutas do PEC de ordem [V DP] e/ou de ordem [DP V], nas construções participiais absolutas licenciadas nos textos dos séculos $X V, X V I$ e $X V I I$, o verbo é realizado em um núcleo de uma categoria funcional projetada em Comp nas ordens [DP V] e [V DP].

Ao propormos que o verbo é realizado no núcleo de uma categoria funcional projetada em posição mais alta que AspP, assumimos, neste trabalho, que as construções participiais absolutas licenciadas nos textos dos séculos XV, XVI e XVII, ainda que defectivas por não projetarem T, projetam o núcleo C.

A projeção de Comp nas construções participiais absolutas do PEC é defendida por Ambar (1992). Por outro lado, Santos (1999) se contrapondo à proposta de Ambar, argumenta não haver evidência empírica independente nas construções do PEC da projeção de Comp. 
A projeção de C também é assumida por Hernanz (1991) ao analisar o uso desse tipo de construção no Espanhol. Segundo essa autora, a ausência de qualquer tipo de conjunção subordinativa nessas orações se deve ao fato de a posição estrutural em Comp não estar mais disponível para sua realização por ter já sido preenchida pelo verbo.

Conforme a resenha apresentada no desenvolvimento do artigo revela, Santos (1999) compara a posição dos advérbios "bem" e "completamente", licenciados nas construções participiais absolutas do PEC, como evidência da realização do verbo em uma posição projetada acima de VP. Para essa autora, a realização do advérbio "completamente" em posição mais alta que o advérbio "bem" nos exemplos por ela fornecidos, que retomamos em (31), (32) e (33), se deve ao fato de o advérbio "completamente" ser mais flexível na definição do seu domínio de adjunção, podendo se realizar em adjunção ao VP ou a um nó mais alto, ao qual "bem" não se adjunge. Diferente da análise de Santos, apoiamonos na posição do argumento verbal com interpretação de tópico para definir a posição do advérbio "assim" nas construções participiais absolutas de ordem VXS/SXV/XSV, formadas no texto de Duarte Galvão. A interpretação de tópico do argumento verbal pode ser tomada como fator empírico que define a realização do elemento adverbial em posição mais alta que VP na estrutura dessas orações. A flexibilidade do advérbio "assim" de adjungir-se a projeções mais altas que VP indica que esse elemento não funciona como advérbio de modo nessas produções. Dentro da hipótese que levantamos neste trabalho, o advérbio "assim" carrega a função de marcador aspectual. O argumento verbal codificado como tópico familiar/tópico contínuo ocupa o [Spec, AspP] nas ocorrências de ordem $V(X) S$, ocupando, por sua vez, o especificador de um núcleo em Comp, que assumimos ser o Spec de kP (contraste) quando a ordem é S(X)V. Nessas produções, o verbo é realizado em um núcleo em Comp. O advérbio "assim" com a função de marcador aspectual pode ser realizado em posição de adjunção à categoria funcional AspP (Aspecto) e/ou em posição de adjunção a outras categorias funcionais projetadas em posições mais altas em Comp.

Esta mesma proposta de análise pode ser usada para a expressão adverbial "tão felizmente" dos exemplos (48) e (49). Este elemento adverbial é realizado em adjunção à categoria funcional AspP.

É a estrutura da informação das ocorrências de ordem VS, como os exemplos (4) e (35), retomados aqui, respectivamente, em (54) e (55), com o argumento verbal interpretado como tópico familiar/tópico contínuo, que se permite propor que este elemento em posição pós-verbal ocupa nessas produções o especificador de AspP.

(54) Feyto efto ElRey cavalguou loguo em hum cavallo grande e fermolo, (Duarte Galvão, séc. XV) 
(55) Despedido o Alvarado, e vinda a monção de se irem pera a India, embarcou Dom Jorge na náo da carreira Belchior Fernandes Correia com todos estes protestos por muitas vias, (D. Couto, séc. XVI).

Antonelli (2008) sustenta que o verbo finito nas sentenças raízes de ordem V2, orações que apresentam o verbo em segunda posição na estrutura da frase, geradas no Português dos séculos XVI e XVII é realizado no núcleo Fin (Finitude) em Comp, seguindo a proposta de Roberts (2004) de que nas línguas de ordem V2, isto é, línguas que apresentam o verbo em segunda posição nas orações matrizes, o núcleo Fin deve apresentar necessariamente uma realização lexical, sendo este requerimento satisfeito nas orações matrizes via movimento do verbo para este núcleo.

Conquanto os dados analisados neste trabalho sejam de orações com verbos no particípio, defendemos que nessas construções o verbo é realizado no núcleo Fin, tendo em conta que este complementizador expressa as propriedades finitas e também as propriedades não finitas de uma oração (RIZZI; BOCCl, 2014).

De modo geral, o fato ressaltado na pesquisa é a diferença das propriedades sintáticodiscursivas emergidas no licenciamento das construções participiais absolutas nos textos dos autores portugueses nascidos nos séculos XV, XVI e XVII e o seu licenciamento no PEC. Conforme a proposta de análise de Santos (1999), o argumento ocorre em posição pré-verbal nas construções do PEC quando carrega a interpretação de tópico; sendo este, segundo Santos, o fator discursivo que motiva a alternância da ordem no uso dessas construções. Nos textos dos séculos XV, XVI e XVII, o argumento codificado como tópico familiar/tópico contínuo ocorre em posição pós-verbal, ocupando a posição pré-verbal quando é um sintagma que expressa contraste/ênfase. Por conseguinte, as construções participiais absolutas formadas nos textos dos autores portugueses dos séculos $X V, X V I$ e XVII apresentam propriedades sintático-discursivas diferentes das propriedades do PEC no uso dessas construções.

\section{Considerações finais}

Buscamos, neste artigo, mostrar que as construções participiais absolutas formadas em textos de autores portugueses nascidos nos séculos XV, XVI e XVII fazem uso de advérbios definidos na literatura como advérbios de VP em posições mais altas na estrutura dessas orações. O respaldo empírico de realização desses advérbios em posição mais alta é assegurado pela posição ocupada pelo argumento verbal com interpretação de tópico familiar/tópico contínuo. Assim considerando, argumentamos que esse tipo de construção nos textos históricos apresenta propriedades sintático-discursivas diferentes das propriedades do PEC. Nessa gramática, a alternância da ordem do argumento verbal ocorre quando este elemento é um tópico. Nos textos históricos investigados nessa pesquisa, o argumento verbal pode ser um tópico mesmo em posição pós-verbal. No 
PEC, de acordo com a análise de Santos (1999), o argumento em posição pós-verbal é sempre o elemento que recebe o acento de foco da oração.

Destacamos o fato de que o texto de Duarte Galvão é o que apresenta regularmente as construções participiais com a alternância da ordem do argumento verbal. Defendemos que o argumento com a interpretação de tópico familiar/tópico contínuo expressa contraste/ênfase, ocupando o Spec de kP (contraste) em Comp.

Mostramos a restrição atestada nos textos dos autores nascidos nos séculos XVI e XVII de uso dessa construção com alternância da ordem do argumento verbal. Sendo este tipo de ocorrência encontrada apenas no texto de Pero Magalhães de Gandavo, autor nascido em 1502; nos textos dos outros autores nascidos nesse período, as orações participiais absolutas dispõem do argumento exclusivamente em posição pós-verbal. Propusemos ser esta restrição motivada por razões discursivas de não licenciamento nesses textos de construção participial absoluta com o argumento verbal expressando contraste/ênfase.

Assim considerando, defendemos neste trabalho que as construções participiais absolutas, ainda que defectivas por não projetarem T, projetam o núcleo C. Como hipótese de trabalho, assumimos que, nas ocorrências de ordem superficial VS com o argumento codificado como tópico familiar/tópico contínuo, este elemento é realizado no Spec, AspP e o verbo ocupa uma posição mais alta, o núcleo Fin em Comp. O advérbio "assim" com a função de marcador aspectual pode ser realizado em posição de adjunção à categoria funcional AspP e/ou em posição de adjunção a outras categorias funcionais projetadas em posições mais altas em Comp.

Nessa linha argumentativa, defendemos que, nas ocorrências licenciadas na ordem VS com o argumento sem a interpretação de tópico familiar/tópico contínuo, este constituinte é foco informacional, sendo realizado na posição interna de sujeito, no especificador de VP.

\section{REFERÊNCIAS}

AMBAR, M. Para uma sintaxe da inversão sujeito-verbo em português. Lisboa: Edições Colibri, 1992. p. 110-118.

ANTONELLI, A. Sintaxe da posição do verbo e mudança gramatical na História do Português Europeu. 2011. Tese (Dourado em Linguística Histórica) - Instituto de Estudos da Linguagem, Universidade Estadual de Campinas, Campinas, 2011.

COSTA, J. Adverbs and the syntax-semantics interplay. Estudos Linguísticos/Linguistic Studies, Edições Colibri/CLUNL, Lisboa, v. 2, p. 13-25, 2008. 
FRACARELLI, M.; HINTERHÖLZL, R. Types of topics in German and Italian. In: WINKLER, S.; SCHWABE, K. (ed.). On information structure, meaning and form. Amsterdam: John Benjamins, 2007. p. 87-116.

GALVES, C. Partial V2 in Classical Portuguese. In: BIBERAUER, T.; WOLFE, S.; WOODS, B. (ed.). Rethinking Verb Second. Oxford: Oxford University Press. (no prelo)

GALVES, C.; GIBRAIL, A. Subject Inversion from Classical to Modern European Portuguese: a Corpus-Based study. In: CARDOSO, A.; MARTINS, A. M. (ed.). Word Order Change. Oxford: Oxford University Press, 2018. p. 163-178.

HERNANZ, M. L. Spanish absolute constructions and aspect. Catalan Working Papers in Linguistics (CWPL). Barcelona: Universitat Autònoma de Barcelona, 1991. p. 1-28. Disponível em: http://bit.ly/2GaReLw. Acesso em: 10 jun. 2017.

KISS, E. Identificational focus versus informative focus. Language, v. 74, n. 2, p. 245-272, 1998.

MICHELAN, K. B. Cronistas medievais: ajuntadores de histórias. História Social, n. 17, p. 265-286, 2009. Disponível em: http://bit.ly/2x19048. Acesso em: 16 ago. 2018.

REINHART, T. Pragmatics and Linguistics: an Analysis of Sentence Topics. Philosophica, Lisbon: Lisbon University, p. 53-94, 1981.

RIZZI, L.; BOSSI, G. The left periphery of the clause. Blackwell Comparation to Syntax. Blackwell Publishers, p. 1-23, 2014. Disponível em: http//unige.ch/lettres/linguistique/ forthcomingtheleftperipheryoftheclause.pdf. Acesso em: 20 ago. 2017.

ROBERTS, I. The C-System in Brythonic Celtic Languages, V2 and the EPP. In: RIZZI, L. (org.). The Structure of CP and IP. The Cartography of Syntactic Structures. v. 2. New York: Oxford University Press, 2004. p. 297-328.

SANTOS, A. L. O particípio absoluto em português e em outras línguas românicas. 1999. Dissertação (Mestrado em Linguística Teórica) - Faculdade de Letras da Universidade de Lisboa, Lisboa, 1999.

ZUBIZARRETA, M. L. The grammatical representation of topic and focus: Implication for the structure of the clause. Working Papers in Linguistics, University of Venice, v. 4, n. 1, p. 97-126, 1994. 
ANEXO

Autores e obras pesquisados

\begin{tabular}{|c|c|c|c|c|}
\hline $\begin{array}{c}\text { Séc. de } \\
\text { nascimento }\end{array}$ & Obra & Autor & $\begin{array}{l}\text { Busca com o } \\
\text { c-search }\end{array}$ & Ocorrências \\
\hline Séc. XV & $\begin{array}{l}\text { Crônica del-Rei D. } \\
\text { Afonso Henriques }\end{array}$ & Duarte Galvão & $\begin{array}{l}\text { Etiquetas } \\
\text { morfológicas }\end{array}$ & 26 \\
\hline \multirow{6}{*}{ Séc. XVI } & $\begin{array}{c}\text { História da Província } \\
\text { de Santa Cruz }\end{array}$ & $\begin{array}{c}\text { Pero Magalhães } \\
\text { de Gandavo }\end{array}$ & Análise sintática & 6 \\
\hline & & $\begin{array}{l}\text { Fernão Mendes } \\
\text { Pinto }\end{array}$ & Análise sintática & 19 \\
\hline & Décadas & Diogo Couto & Análise sintática & 29 \\
\hline & Monarchia Lusitana & António Brandão & $\begin{array}{l}\text { Etiquetas } \\
\text { morfológicas }\end{array}$ & 2 \\
\hline & $\begin{array}{l}\text { Da Monarquia } \\
\text { Lusitana }\end{array}$ & Bernardo de Brito & $\begin{array}{l}\text { Etiquetas } \\
\text { morfológicas }\end{array}$ & 3 \\
\hline & $\begin{array}{c}\text { A vida de Frei } \\
\text { Bertolameu dos } \\
\text { Mártires }\end{array}$ & Luis de Sousa & $\begin{array}{l}\text { Análise } \\
\text { sintática }\end{array}$ & 4 \\
\hline \multirow{6}{*}{ Séc. XVII } & $\begin{array}{l}\text { Vida do apostólico } \\
\text { padre Antonio Vieira }\end{array}$ & André de Barros & $\begin{array}{l}\text { Análise } \\
\text { sintática }\end{array}$ & 19 \\
\hline & A arte de furtar & Manuel da Costa & Análise sintática & 3 \\
\hline & $\begin{array}{c}\text { Vida e Morte de } \\
\text { Madre Helena da } \\
\text { Cruz }\end{array}$ & Maria do Céu & Análise sintática & 2 \\
\hline & Mercúrio Português & $\begin{array}{c}\text { António de Sousa } \\
\text { de Macedo }\end{array}$ & $\begin{array}{c}\text { Etiquetas } \\
\text { morfológicas }\end{array}$ & 12 \\
\hline & Tácito Português & $\begin{array}{c}\text { Francisco Manuel } \\
\text { de Melo }\end{array}$ & $\begin{array}{l}\text { Etiquetas } \\
\text { morfológicas }\end{array}$ & 1 \\
\hline & História do Futuro & Antonio Vieira & $\begin{array}{l}\text { Etiquetas } \\
\text { morfológicas }\end{array}$ & 3 \\
\hline
\end{tabular}

